
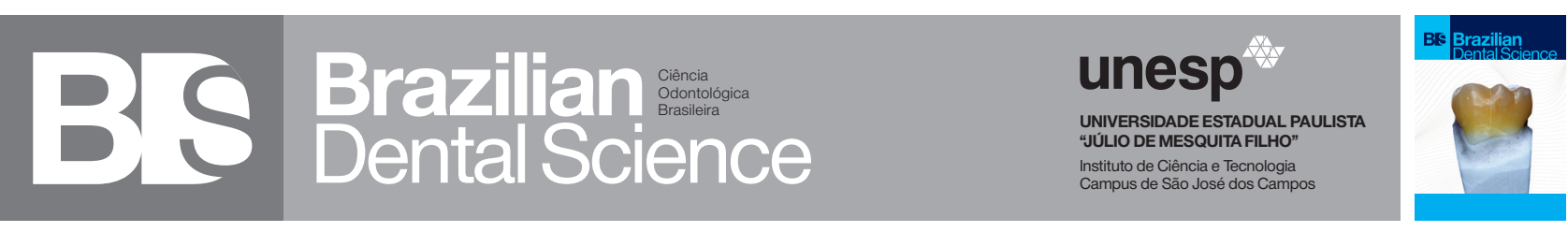

\title{
How do the optical properties of the bulk fill posterior composites change after 2 years of simulated toothbrushing?
}

\author{
Como as propriedades ópticas de compósitos bulk fill se comportam após 2 anos de escovação simulada?
}

\author{
Letícia de Souza LOPES ${ }^{1}$, Helio Rodrigues Sampaio FILHO ${ }^{1}$, Elisa Gomes ALBUQUERQUE ${ }^{2}$, Chane TARDEM ${ }^{2}$, Marcos Oliveira \\ BARCELEIRO $^{2}$, Mauro Sayão de MIRANDA ${ }^{1}$ \\ 1 - Department of Restorative Dentistry - School of Dentistry - Rio de Janeiro State University - Rio de Janeiro - RJ - Brazil. \\ 2 - Department of Restorative Dentistry - School of Dentistry - Fluminense Federal University - Nova Friburgo - RJ - Brazil.
}

\section{ABSTRACT}

Objective: The objective of this study was to evaluate the alteration of the optical properties of bulk fill resin-based composites after two years of simulated toothbrushing. Material and Methods: Three high-viscosity bulk fill resin composites and one conventional sculptable resin composite (control) were analyzed. Five specimens of each resin composite were prepared, and roughness, color, translucency and gloss were evaluated initially and after one and two years of simulated toothbrushing. The specimens were submitted to electric simulated toothbrushing (14600 strokes / 100 g) using a commercially available soft bristle toothbrush and toothpaste slurry in a proportion of $1: 2$ by weight. The brushing scheme was of 40 cycles per day ( 2 cycles per second / 280 cycles in a week). The optical properties and the roughness data were analyzed by a multifactor analysis of variance (MANOVA) and a Tukey post hoc test. Results: The baseline and final values of Ra and Sa were submitted to linear regression analyses, all of which were performed at a significance level of $5 \%$. Gloss and roughness presented statistical differences between the resin-time interactions in all composite resins. The gloss $(72.5 \%)$ and roughness (89.4\%) worsened significantly after brushing, but the authors didn't find statistically significant differences when evaluating translucency and color. Conclusion: Based in the results, it could be concluded that the simulated brushing degraded the gloss and roughness of the used high-viscosity bulk fill composites.

\section{KEYWORDS}

Optical stability; Roughness; Simulated toothbrushing; Bulk fill resin-based composite.

\section{RESUMO}

Objetivo: O objetivo deste estudo foi avaliar a alteração das propriedades ópticas de resinas compostas do tipo bulk fill após dois anos de escovação simulada. Material e Métodos: Foram analisadas três resinas compostas do tipo bulk fill de alta viscosidade e uma resina composta convencional (controle). Cinco corpos-deprova de cada resina composta foram preparados e a rugosidade, cor, translucidez e brilho foram avaliados inicialmente e após um e dois anos de escovação simulada. Os espécimes foram submetidos a escovação dental simulada (14.600 golpes / 100 g) utilizando-se escova de dentes de cerdas macias comercialmente disponíveis e uma pasta composta de dentifrício e água na proporção de 1:2 em peso. O esquema de escovação foi de 40 ciclos por dia (2 ciclos por segundo / 280 ciclos por semana). As propriedades ópticas e os dados de rugosidade foram analisados por uma análise de variância multifatorial (MANOVA) e um teste post hoc de Tukey. Resultados: Os valores iniciais e finais de Ra e Sa foram submetidos a análises de regressão linear, todas realizadas ao nível de significância de $5 \%$. O brilho e a rugosidade apresentaram diferenças estatísticas entre as interações resina-tempo em todas as resinas compostas. $\mathrm{O}$ brilho $(72,5 \%)$ e a rugosidade $(89,4 \%)$ pioraram significativamente após a escovação, mas os autores não encontraram diferenças estatisticamente significativas ao avaliar a translucidez e a cor. Conclusão: Com base nos resultados, pôde-se concluir que a escovação simulada degradou o brilho e a rugosidade das resinas compostas do tipo bulk fill avaliadas.

\section{PALAVRAS-CHAVE}

Estabilidade ótica; Rugosidade; Escovação dentária simulada; Resina composta bulk fill. 


\section{INTRODUCTION}

S ince Bowen reported the first successful resin-based composite material in the early 1960s [1], manufacturers have been trying to improve the physical and mechanical properties of these materials [2,3]. Direct composites have become increasingly popular as first-choice materials to restore extensive lesions in anterior or posterior teeth [4], mainly because of the esthetic advantages. They are able to mimic the surface smoothness, color, translucency and glossy appearance of dental tissues as closely as possible, thereby creating "invisible" restorations close to natural teeth [5].

In order to achieve this satisfactory esthetic result, however, it is known that all stages of restoration must be well conducted, but certainly a good sculpture, reproducing the anatomy of the missing dental portion, as well as the recovery of its gloss and texture, and especially the maintenance of these characteristics over the years, are fundamental to achieve the natural appearance of restorations [6]. Some characteristics that may facilitate or hinder the obtaining and maintenance of these properties in a restoration include resin composite type, resin monomer, concentration and type of filler particles, and the finishing/polishing system used, among others [7].

The recently launched bulk fill composite resins are materials that exhibit a reduction in the stress generated by the polymerization contraction, and can be light-cured in increments up to $5 \mathrm{~mm}$ thick, which allows them to be introduced at once into the cavity [8]. They are indicated mainly for restorations in posterior teeth, being considered easy to use and friendlier than the meticulous and traditional incremental techniques required for conventional composite resins [9].

A problem still observed in restorations in posterior teeth performed with bulk fill resins, however, is the degradation that they can suffer in the oral environment. This degradation process may lead to several drawbacks, such as an increase in wear and surface roughness $[10,11]$, which can increase biofilm adhesion and consequently increase the risk of secondary caries and periodontal disease. This problem is usually solved with mechanical toothbrushing, but it is known that this mechanical brushing may cause resin composite abrasion [12], which increases the surface roughness of resin composites, accelerating the staining produced by pigments from beverages and interfering with color appearance [13-15] and with the esthetic result obtained over time. The studies that did these evaluations were carried out with traditional composite resins, but to date, it is not known if the same effects can occur with the new bulk fill resins.

Therefore, the objective of this study was to evaluate if toothbrushing cycle can change significantly the optical properties and the topography of bulk fill resin-based composites. The null hypothesis tested was that brushing after two years would not affect the optical and topography properties of bulk fill composites. To evaluate that hypothesis, this study evaluated whether the roughness of the resins will increase after brushing, whether the translucency will decrease after brushing, and whether the gloss will decrease after brushing.

\section{MATERIAL AND METHODS}

Four resin-based composites (RBC) were analyzed, three high viscosity bulk fill, and one conventional sculptable RBC, used as a control group: Aura Bulk Fill (SDI, Victoria, Australia), Tetric N-Ceram Bulk Fill (Ivoclar, Schaan Liechtenstein), Filtek Bulk Fill Posterior Restorative (3M ESPE, St Paul, MN, USA), and Filtek Supreme Ultra (3M ESPE), also known as Filtek Z350XT or Filtek Supreme XTE in some countries. The material details are described in Table I. 
Table I - Materials used in the experiments

\begin{tabular}{|c|c|}
\hline Composite resin & Composition \\
\hline $\begin{array}{l}\text { Aura Bulk Fill (SDI) } \\
\text { Lot: } 150557\end{array}$ & $\begin{array}{c}\text { Resin Matrix:UDMA (diurethane dimetha- } \\
\text { crylate) / BisEMA (bisphenol-A-polyethyle- } \\
\text { ne glycol diether dimethacrylate) / BisGMA } \\
\text { (bisphenol-A-diglicil dimethacrylate); } \\
\text { Fillers: Barium aluminosilicate pre-polymeri- } \\
\text { zed filler; amorphous silicon dioxide, } 81 \text { wt\%, } \\
65 \text { vol\%. } \\
\text { Particle size: } 0.02-0.4 \text { ym } \\
\text { Photoinitiator:Camphorquinone }\end{array}$ \\
\hline $\begin{array}{l}\text { Filtek Bulk Fill Posterior } \\
\text { Restorative (3M ESPE) } \\
\text { Lot: } 1521500378\end{array}$ & $\begin{array}{l}\text { Resin Matrix: AUDMA (urethane aromatic } \\
\text { dimethacrylate) / UDMA / 1,12-dodecane-D- } \\
\text { MA (12-dodecane dimethacrylate); } \\
\text { Fillers: Combination of a non-agglomerated/ } \\
\text { non-aggregated } 20 \mathrm{~nm} \text { silica filler, a non-a- } \\
\text { gglomerated/ non-aggregated } 4 \text { to } 11 \mathrm{~nm} \\
\text { zirconia filler, an aggregated zirconia/silica } \\
\text { cluster filler (comprised of } 20 \text { nm silica and } \\
4 \text { to } 11 \mathrm{~nm} \text { zirconia particles) and a ytterbium } \\
\text { trifluoride filler consisting of agglomerate } \\
100 \text { nm particles; } 76.5 \text { wt\%, } 58.4 \text { vol\%. } \\
\text { Photoinitiator: Camphorquinone }\end{array}$ \\
\hline $\begin{array}{l}\text { Tetric N-Ceram Bulk Fill } \\
\text { (Ivoclar Vivadent) } \\
\text { Lot:U27917 }\end{array}$ & $\begin{array}{c}\text { Resin Matrix: Bis-GMA / UDMA / Bis-EMA } \\
\text { (bisphenol-A-polyethylene glycol diether } \\
\text { dimethacrylate); } \\
\text { Fillers: barium aluminium silicate glass, an } \\
\text { "Isofiller", ytterbium fluoride and spherical } \\
\text { mixed oxide; } 77 \text { wt } \%, 61 \text { vol\%. } \\
\text { Particle size: between } 0.04 \text { and } 3 \text { ym. The } \\
\text { mean particle size is } 0.6 \text { ym } \\
\text { Photoinitiator: camphorquinone plus an acyl } \\
\text { phosphine oxide, } \\
\text { together with a patented initiator Ivocerin }\end{array}$ \\
\hline $\begin{array}{c}\text { Filtek Supreme Ultra } \\
\text { (3MESPE) } \\
\text { Lot:1615300591 }\end{array}$ & $\begin{array}{c}\text { Resin Matrix: Bis-GMA / Bis-EMA / UDMA } \\
\text { / TEG-DMA (polyethylene glycol dimetha- } \\
\text { crylate, triethylene glycol); } \\
\text { Fillers: Combination of a non-agglomera- } \\
\text { ted/non-aggregated } 20 \text { nm silica filler, a } \\
\text { non-agglomerated/ non-aggregated } 4 \text { to } \\
11 \text { nm zirconia filler, an aggregated zirconia/ } \\
\text { silica cluster filler (comprised of } 20 \mathrm{~nm} \text { silica } \\
\text { and } 4 \text { to } 11 \mathrm{~nm} \text { zirconia particles); } 78.5 \text { wt\%, } \\
66.3 \text { vol\%. } \\
\text { Photoinitiator:Camphorquinone }\end{array}$ \\
\hline
\end{tabular}

\section{Specimen Preparation}

The materials were bulk inserted into a stainless steel mold measuring $9 \mathrm{~mm}$ in diameter and $4 \mathrm{~mm}$ in height. The mold was covered with a mylar strip and a glass slide ( $0.7 \mathrm{~mm}$ thick). Lightcuring of the restorative materials was performed using the Radii Cal (SDI, Victoria, Australia) light unit, with a power of $1200 \mathrm{~mW} / \mathrm{cm}^{2}$, the power of which was evaluated before each lightcuring procedure with a radiometer (Hilux Led Max Curing light meter, First Medica, Greensboro, NC, USA). Five specimens were prepared for each composite. After this, the top surfaces of the specimens were sequentially wet polished with 1200, 2500 and 4000 grit Silicon carbide (SiC) paper (DPU-10, Struers, Copenhagen, Denmark).

\section{Surface Roughness Analysis}

In order to evaluate the surface roughness, the authors used a surface roughness tester (Surftest SJ 201, Mitutoyo, Tokyo, Japan). Four traces of roughness, spaced at $45^{\circ}$ with a $0.8 \mathrm{~mm}$ cutoff and speed of $0.1 \mathrm{~mm} / \mathrm{s}$, were recorded for each specimen, and the average surface roughness $\left(\mathrm{R}_{\mathrm{a}}-\mathrm{mm}\right)$ was determined. The $R_{a}$ parameter was obtained using the following formula:

$$
R_{a}=\frac{1}{L} \int_{0}^{L}|f(x)| d x
$$

Where $\mathrm{L}$ is the length of the section and $f(x)$ is the displacement function.

\section{Color and translucency Analysis}

A pre-calibrated spectrophotometer (model CM2600d, Konica Minolta Sensing Inc, Osaka, Japan) was used to evaluate the color of all specimens according to the CIE $\mathrm{L}^{*} \mathrm{a} * \mathrm{~b} *$ system. A D65 illuminant was used with a $45^{\circ}$ entrance angle and $10^{\circ}$ observation angle geometry. To guarantee the consistency of consecutive and repeated measurements of CIE L*a*b* parameters, a device was developed that was precisely attached to the base unit of the spectrophotometer, where a white and a black spectrophotometry ceramic standard (Konica Minolta Sensing Inc,) was positioned. This procedure allowed the color and translucency to be consistently measured in the central area and at the same position for all the specimens. The L* (Lightness), a* (Red/green coordinate), and b* (yellow/ blue coordinate) values of each specimen were separately measured in triplicate against the white and the black background. 


\section{Gloss Analysis}

A small-area glossmeter (ZGM 1110, Zehntner testing instruments, Sissach, Switzerland) with a square measurement area of $2 \mathrm{~mm} \times 2 \mathrm{~mm}$ and $20^{\circ}$ geometry was used to measure gloss, expressed in gloss units (GU). The gloss was measured in triplicate for each specimen.

\section{Topographic Analysis}

The topographic analysis was performed using a three-dimensional (3D) profilometer (Form Talysurf 60i, Taylor Hobson, Leicester, UK). For each specimen, an area of $1 \mathrm{~mm}^{2}$ was scanned with a 20 -nm z-resolution, employing 4000 steps in the $\mathrm{x}$-axis and a spacing of 2 $\mathrm{mm}$ in the $\mathrm{y}$-axis. The roughness of the 3D reconstructed image was obtained using the 3D $\mathrm{S}_{\mathrm{a}}$ parameter (average absolute deviation of the surface), using the following equation:

$$
S \boldsymbol{a}=\frac{1}{M N} \sum_{k=0}^{M-1} \sum_{l=0}^{N-1}\left|z\left(x_{k} ; y_{1}\right)\right|
$$

Where $\mathrm{z}$ is the height of the measured point in the coordinates $\mathrm{x}$ and $\mathrm{y}$.

\section{Toothbrushing simulation and properties reevaluation}

After taking the baseline measurements, the specimens $(n=5)$ were submitted to electric simulated toothbrushing (14600 strokes/ 100g) using a commercially available soft bristle toothbrush (Oral B 30, Procter \& Gamble, SP, Brazil) and toothpaste slurry in a proportion of 1:2 by weight (70 $\mathrm{g}$ of Oral B 1,2,3 [Procter \& Gamble] and $140 \mathrm{ml}$ of distilled water) in a brushing machine (MEV2, Odeme Biotecnology, Joaçaba, SC, Brazil). The brushing scheme was of 40 cycles per day (2 cycles per second / 280 cycles in a week) [16].

This cycle was repeated two times (one in each week) and all the evaluations were performed between the two cycles and after the second cycle. Each cycle simulates one year of toothbrushing. In the intervals, the specimens were stored in distilled water.
The color change (DeltaE) for each specimen was calculated from the mean $\mathrm{DL}^{*}$, $\mathrm{Da}^{*}, \mathrm{Db}^{*}$ values, obtained against the white background, using the following formula:

$$
\mathrm{DE}=\left(\mathrm{DL}^{* 2}+\mathrm{Da}^{* 2}+\mathrm{Db}^{* 2}\right)^{1 / 2}
$$

where $\mathrm{DL}^{*}, \mathrm{Da}^{*}, \mathrm{Db}^{*}$ are the differences in $\mathrm{L}^{*}$, $a^{*}$ and $b^{*}$ values, before and after each period of evaluation ( 1 and 2 years / 1 and 2 cycles respectively) of toothbrushing simulation, respectively.

The translucency parameter (TP) for each specimen after each one-week period was calculated using the following formula: $-\mathrm{b} * \mathrm{~W})]^{1 / 2}$

$$
\mathrm{TP}=\left[(\mathrm{Lb}-\mathrm{Lw})^{2}+(\mathrm{a} * \mathrm{~B}-\mathrm{a} * \mathrm{w})^{2}+(\mathrm{b} * \mathrm{~B}\right.
$$

where the subscript $\mathrm{B}$ and $\mathrm{W}$ letters represent the measurements against the black and white backgrounds, respectively.

\section{SEM analysis}

In order to characterize the effect of toothpaste slurry and simulated toothbrushing on the surface morphology of RBCs, two additional specimens from each RBC were prepared, as described previously, and two specimens from each group, randomly chosen after the experimental protocol (2 cycles / 2 years of toothbrushing simulation), were observed under a scanning electron microscope, in order to compare the surfaces before and after toothbrush simulation. The specimens were mounted on aluminum stubs, sputter-coated with Au-Pd (EMITECH model K550, Emitech; Ashford, Kent, UK), and observed by SEM (JSMiT300LV, JEOL; Tokyo, Japan) operating in the secondary electron mode. The SEM images were taken at x 2500 .

\section{Statistical analysis}

The obtained data were analyzed using Statgraphics Centurion XVI software (StatPoint Technologies Inc, Warrenton, VA, USA). Initially, the normal distribution of the errors and the homogeneity of variances were evaluated by the Shapiro-Wilk and Levene tests. Based on these preliminary analyses, the roughness data were 
analyzed by a multifactor analysis of variance (MANOVA) and a Tukey post hoc test. The baseline and final values of $\mathrm{Ra}$ and Sa were submitted to linear regression analyses, all of which were performed at a significance level of $5 \%$. Color, translucency and gloss data were also evaluated by a multifactor analysis of variance (MANOVA) and Tukey post hoc test at a significance level of $5 \%$.

\section{RESULTS}

The MANOVA showed statistically significant differences between the used RBCs ( $p$ $<0.05$ ) for color (Delta E). In contrast, there was no significant difference for time inside the groups, after 1 or 2 years of brushing simulation ( 1 and 2 cycles of 1 week). The mean differences in color between the initial restoration and after brushing simulation for two years are shown in Table II.

Table II - Mean (SD) differences in color between the initial and after 1-year and 2-years brushing simulation

\begin{tabular}{|ccc|}
\hline Group & Baseline X 1year & Baseline x 2years \\
\hline Aura Bulk Fill & $0.91(0.09)^{\mathrm{AB}}$ & $0.63(0.08)^{\mathrm{B}}$ \\
\hline Filtek Bulk Fill Posterior & $1.66(0.12)^{\mathrm{C}}$ & $1.81(0.14) \mathrm{C}$ \\
\hline Tetric N-Ceram Bulk Fill & $1.01(0.18)^{\mathrm{AB}}$ & $1.43(0.25)^{\mathrm{AC}}$ \\
\hline Filtek Supreme Ultra & $0.81(0.10)^{\mathrm{B}}$ & $0.95(0.09)^{\mathrm{AB}}$ \\
\hline
\end{tabular}

In table, in means followed by the same uppercase letter (A, $B, C)$ indicates that differences were statistically not significant (Tukey HSD, $p>0.05$ )

The same test showed translucency statistically significant differences $(\mathrm{p}<0.05)$ when comparing materials $(\mathrm{p}=0.01)$ and time $(\mathrm{p}=$ 0.04). Comparisons of translucency average values in the different evaluation times are presented in Table III. The authors found statistically significant differences between initial time and 2 years when using Filtek Bulk Fill Posterior Restorative and Tetric N-Ceram Bulk Fill.
Table III - Comparisons of translucency average values (SD) in the different evaluation times

\begin{tabular}{|c|c|c|c|}
\hline Composite Resin & Baseline & 1 year & 2 years \\
\hline Aura Bulk Fill & $11.308(0.471)^{\mathrm{aAB}}$ & $11.926(0.516)^{\mathrm{aB}}$ & $12.476(0.699){ }^{a}{ }^{a B}$ \\
\hline $\begin{array}{l}\text { Filtek Bulk Fill Pos- } \\
\text { terior }\end{array}$ & $12.988(0.217)^{\mathrm{bA}}$ & $13.348(0.653)^{\mathrm{bAB}}$ & В $14.518(0.543)^{\mathrm{bB}}$ \\
\hline $\begin{array}{l}\text { Tetric N-Ceram Bulk } \\
\text { Fill }\end{array}$ & $14.342(0.593)^{C A}$ & $15.604(0.673)^{\text {сAB }}$ & $16.442(0.488)^{\text {св }}$ \\
\hline Filtek Supreme Ultra & $7.664(0.462)^{d A}$ & $8.292(0.397)^{\mathrm{dA}}$ & $8.618(0.519) \mathrm{dA}$ \\
\hline
\end{tabular}

In columns, means followed by the same lowercase letter ( $\mathrm{a}$, $b, c)$ indicates that differences were statistically not significant (Tukey HSD, $p>0.05$ ). In rows, means followed by the same uppercase letter $(A, B, C)$ indicates that differences were statistically not significant (Tukey HSD, $p>0.05$ ).

The MANOVA showed statistically significant differences for gloss when comparing materials $(\mathrm{p}=0.01)$, time $(\mathrm{p}=0.00)$ and considering the interaction time $\mathrm{x}$ material $(\mathrm{p}=$ 0.02). Comparisons of average gloss values in the different evaluation times are described in Table IV. Table V shows the statistical differences considering interaction time versus material.

Table IV - Comparisons of gloss average (SD) values in the different evaluation times

\begin{tabular}{|c|c|c|c|}
\hline Composite Resin & Baseline & 1year & 2 years \\
\hline Aura Bulk Fill & $74.52(287)^{\mathrm{aA}}$ & $27.72\left(0.84^{\mathrm{aaB}}\right.$ & $19.02(1.88)^{a b c}$ \\
\hline $\begin{array}{l}\text { Filtek Bulk Fill Pos- } \\
\text { terior }\end{array}$ & $83.92(2.32)^{\mathrm{bA}}$ & $22.56(2.91)^{\mathrm{bB}}$ & $16.20(2.11)^{b c}$ \\
\hline $\begin{array}{l}\text { Tetric N-Ceram Bulk } \\
\text { Fill }\end{array}$ & $75.48(3.12)^{\mathrm{aA}}$ & $26.5(253)^{a b B}$ & $20.12(1.08)^{a c}$ \\
\hline Filtek Supreme Ultra & $86.88(3.06)^{\mathrm{bA}}$ & $36.68(3.28)^{c B}$ & $33.26(3.80)^{\text {св }}$ \\
\hline
\end{tabular}

In columns, means followed by the same lowercase letter ( $a, b$, $c, d)$ indicates that differences were statistically not significant (Tukey HSD, $p>0.05$ ). In rows, means followed by the same uppercase letter $(A, B, C)$ indicates that differences were statistically not significant (Tukey HSD, $p>0.05$ ).

Table V - Comparison of gloss average (SD) considering interaction time $\mathrm{x}$ material

\begin{tabular}{|c|c|c|c|}
\hline Composite Resin & Baseline & 1 year & 2 years \\
\hline Aura Bulk Fill & $74.52(2.87)^{\mathrm{B}}$ & $27.72(0.84)^{D}$ & $19.02(1.88)^{F G}$ \\
\hline $\begin{array}{c}\text { Filtek Bulk Fill Pos- } \\
\text { terior }\end{array}$ & $83.92(2.32)^{A}$ & $22.56(2.91)^{E F}$ & $16.20(2.11)^{\mathrm{G}}$ \\
\hline $\begin{array}{l}\text { Tetric N-Ceram Bulk } \\
\text { Fill }\end{array}$ & $75.48(3.12)^{\mathrm{B}}$ & $26.5(253)^{\mathrm{DE}}$ & $20.12(1.08)^{F}$ \\
\hline Filtek Supreme Ultra & $86.88(3.06)^{A}$ & $36.68(3.28)^{c}$ & $33.26(3.80)^{c}$ \\
\hline
\end{tabular}


When evaluating roughness, there were statistically significant differences when comparing materials $(\mathrm{p}=0.008)$, time $(\mathrm{p}=0.00)$, and double interaction time $\mathrm{x}$ material $(\mathrm{p}=0.01)$. Comparisons of average roughness values in the different evaluation times are shown in Table VI. The RBCs Aura Bulk Fill and Tetric N-Ceram Bulk Fill showed statistically significant differences between 1 and 2 years of brushing simulation, while the RBCs Filtek Bulk Fill posterior restorative and Filtek Supreme Ultra have not presented any difference between the initial and 1 year simulation time. Table VII shows the statistical differences regarding interaction time versus material.

Table VI - Comparisons of roughness average values (SD) in the different evaluation times

\begin{tabular}{|c|c|c|c|}
\hline Composite Resin & Baseline & 1year & 2 years \\
\hline Aura Bulk Fill & $0.068(0.016)^{\mathrm{aA}}$ & $0.520(0.058)^{a, B}$ & $0.810(0.073)^{\mathrm{a} a \mathrm{C}}$ \\
\hline $\begin{array}{c}\text { Filtek Bulk Fill Pos- } \\
\text { terior }\end{array}$ & $0.052(0.018)^{a A}$ & $0.256(0.067)^{b c, B C}$ & $0.376(0.075)^{b c c c}$ \\
\hline $\begin{array}{l}\text { Tetric N-Ceram Bulk } \\
\text { Fill }\end{array}$ & $0.070(0.017)^{\mathrm{aA} A}$ & $0.484(0.036)^{\mathrm{a}, \mathrm{B}}$ & $0.692(0.048)^{a, c}$ \\
\hline Filtek Supreme Ultra & $0.046(0.019)^{\mathrm{aA}}$ & $0.164(0.063)^{b, B}$ & $0.234(0.072)^{b d, B C}$ \\
\hline
\end{tabular}

In columns, means followed by the same lowercase letter ( $a, b$, $c, d)$ indicates that differences were statistically not significant (Tukey HSD, $p>0.05$ ). In rows, means followed by the same uppercase letter $(A, B, C)$ indicates that differences were statistically not significant (Tukey HSD, $p>0.05$ ).

Table VII - Comparison of roughness average (SD) considering interaction time $\mathrm{x}$ material

\begin{tabular}{|cccc|}
\hline Composite Resin & Baseline & 1year & 2 years \\
\hline Aura Bulk Fill & $0.068(0.016)^{A}$ & $0.520(0.058)^{\mathrm{D}}$ & $0.810(0.073)^{\mathrm{E}}$ \\
\hline $\begin{array}{c}\text { Filtek Bulk Fill Pos- } \\
\text { terior }\end{array}$ & $0.052(0.018)^{\mathrm{A}}$ & $0.256(0.067)^{\mathrm{BC}}$ & $0.376(0.075)^{\mathrm{CD}}$ \\
\hline $\begin{array}{c}\text { Tetric N-Ceram Bulk } \\
\text { Fill }\end{array}$ & $0.070(0.017)^{\mathrm{A}}$ & $0.484(0.036)^{\mathrm{D}}$ & $0.692(0.048)^{\mathrm{E}}$ \\
\hline Filtek Supreme Ultra & $0.046(0.019)^{\mathrm{A}}$ & $0.164(0.063)^{\mathrm{B}}$ & $0.234(0.072)^{\mathrm{BC}}$ \\
\hline
\end{tabular}

In table, means followed by the same uppercase letter (A, B, $C, D$ ) indicates that differences were statistically not significant (Tukey HSD, $p>0.05$ )

Figure 1 shows representative micrographs of each composite before and after simulated toothbrushing. At baseline, all the materials showed smoother surfaces, and the authors didn't find any significant statistical difference regarding roughness. However, after 2 years of simulated toothbrushing, micromorphological changes on surfaces of all composites could be verified.
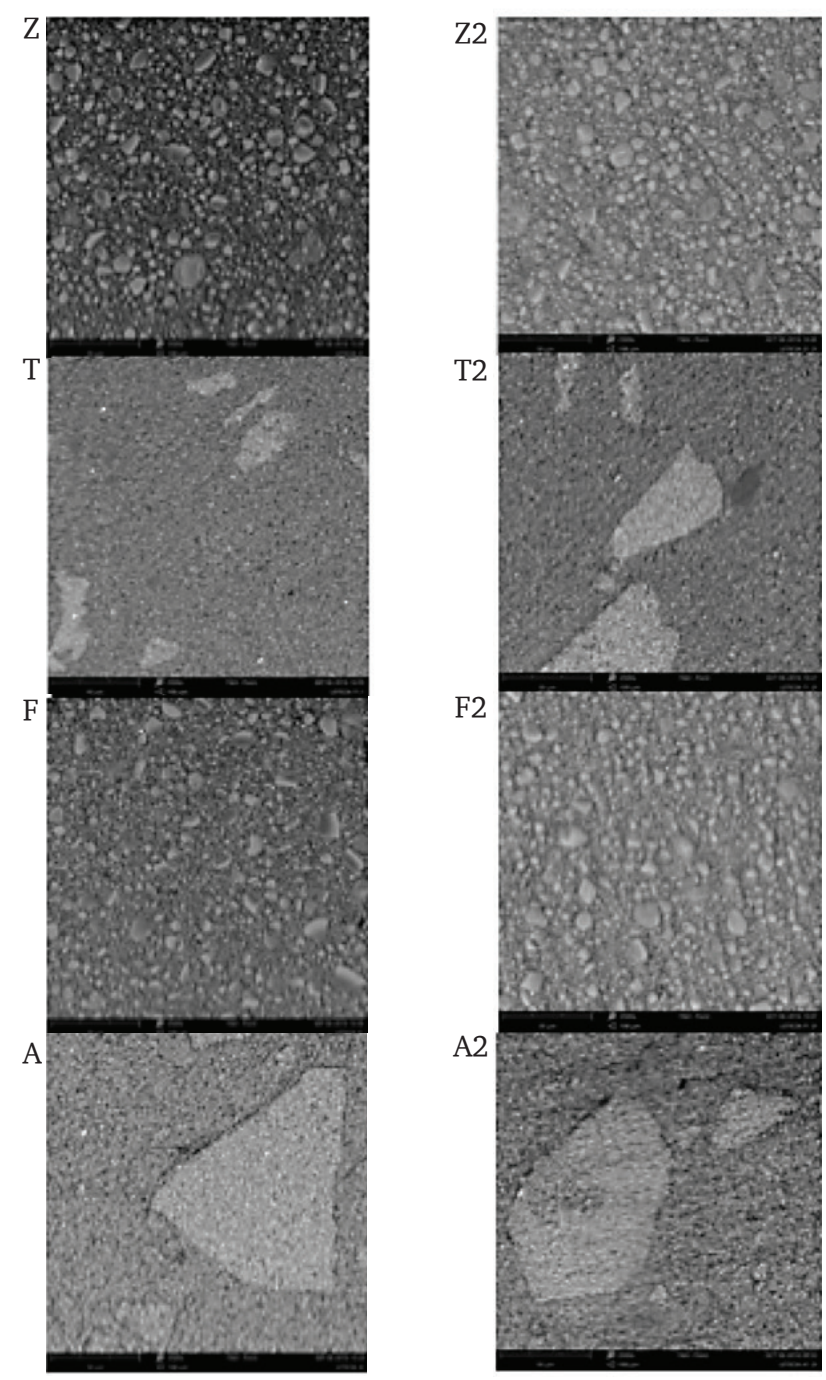

Figure 1 - Representative micrographs of each composite before and after simulated toothbrushing. Z- initial image of Filtek Supreme Ultra resin; Z2- image after two years of toothbrushing simulation of the Filtek Supreme Ultra resin; Tinitial image of Tetric N-Ceram Bulk Fill resin; T2-image after two years of toothbrushing simulation of the Tetric N-Ceram Bulk Fill resin; A- initial Aura Bulk Fill resin image; A2- image after two years of toothbrushing simulation of the Aura Bulk Fill resin; F- initial image of Filtek Bulk Fill; F2- image after two years of toothbrushing simulation of the Filtek Bulk Fill resin. 


\section{DISCUSSION}

Traditionally, composites are used in 2 $\mathrm{mm}$ increments with a horizontal or oblique technique to ensure optimum light penetration and conversion degree. However, restoring cavities in 2-mm-thick increments is very time consuming, and void spaces can be included, which causes a greater risk of contamination between layers [17].

Single increments are highly desired in the restorative practice routine, but concerns about shrinkage stress have caused some reluctance in their application [18]. Composite resin manufacturers have already made many attempts to reduce polymerization shrinkage. One way of doing this was the introduction of silorane-based resin composites. However, studies have reported that the attempt to reduce this contraction through the ring opening present in the silorane monomer was inconclusive in terms of efficacy [19]. The reduction in the polymerization shrinkage of silorane-based composite resins showed no advantage over methacrylate-based resin composites in terms of clinical performance, and the physical and mechanical properties of the silorane-based resins were comparable or inferior to methacrylate-based resins in in vitro studies [20].

In general, manufacturers of the recent introduced bulk fill composites were able to improve the depth of polymerization through the use of powerful photoinitiator systems together with a higher translucency $[21,22]$. The last generation of bulk fill composite has a higher content of filler and claims to have improved mechanical properties. As a result, they are now also recommended for larger posterior restorations [23].

Although many studies on various aspects of bulk fill composites have already shown their advantageous characteristics, no studies have been done to characterize the optical properties of these resins, as the authors did in this study.

With the esthetic evidence in dentistry, the requirements become much greater, and the need for satisfactory optical properties in composite resins is increasing. This means that characteristics, such as translucency, gloss, color, and surface texture similar to those of dental tissues are increasingly valued, and the maintenance of these characteristics, over time, is sought by manufacturers. Based on this statement, this study aimed to assess these characteristics related to bulk fill composites, comparing all these characteristics at the time the restorations are done and after 1 or 2 years of use and wear by simulated toothbrushing.

In this study, the brushing scheme was based on an estimate that one tooth is brushed for $10 \mathrm{~s}$ at each brushing daily of $2 \mathrm{~min}$. Considering that a person brushes the teeth twice a day, this means that each tooth will be submitted, on average, to 40 cycles per day (2 cycles per second / 280 cycles in a week) [16].

In this study, we found a great change in the roughness after 1 and 2 years of simulated brushing, but the small difference between the resins was a surprise. The roughness clinically influences the behavior of the resins through the facilitation of biofilm adhesion to the dental surface [24] and the modification of the way the light reflects on the dental surface, thus altering the perception of color, translucency, and gloss. Thus, the evaluations through a surface roughness tester and a 3D profilometer were of great value in identifying how affected the surface of the resin was and if there was a way the bulk composites could be more or less affected than a conventional resin present in the market with the daily brushing. The greater the roughness after some period of brushing, the greater the lack of gloss and greater opacity, besides reflecting clinically in a greater accumulation of dental biofilm. It was initially possible to verify a difference in the polishing capacity of the materials. The Filtek Bulk Fill Posterior and Filtek Supreme Ultra composites showed less roughness than the Aura Bulk Fill and Tetric N-Ceram composites. In addition, the conventional composite presented higher surface gloss than those of the bulk fill type. In terms of the brushing cycles, all bulk fills 
lost gloss and roughness, but the Aura Bulk Fill and Tetric N-Ceram resins were affected more strongly. This is probably related to the differences presented by the RBCs in terms of inorganic particle sizes (Table I). The Filtek Bulk Fill Posterior Restorative and Filtek Supreme Ultra have smaller and more regular inorganic particles than the Aura Bulk Fill and Tetric $\mathrm{N}$-Ceram particles, which present irregular matrix-dispersed clusters. This fact could be verified through SEM (Figure 1).

In the Filtek Bulk Fill Posterior Restorative composite, the bulk fill behaves differently from the other composites, which can be explained by the fact that it is the only composite with the AUDMA monomer, which was not found in the other composites. The effectiveness of the bulk fill composite without AUDMA is questioned, as it is a polymer considered more reactive and more mobile than others, allowing for the technique of bulk-filling. This finding confirms a previous study [25], where the authors asserted that some bulk fill composites are nothing more than conventional composites with higher translucency.

Translucency is the ability of a material to transmit and disperse light, which is extremely important for the naturalness of the restorations. In composite resins, this property can be influenced by the polymer matrix, inorganic particles, and the layer thickness [26]. In the present study, the translucency remained little altered, presenting no statistical difference in the time-material interaction. However, the Filtek Supreme Ultra was more stable with the brushing time than the bulk type resins.

A significant difference was shown between the gloss of the conventional resin and the bulk at the time of brushing and considering the interaction time versus material. It is believed that the conventional nano-filled resin results in a higher initial gloss and a greater capacity to maintain that gloss even after aggressions to the oral environment because of its better polishing. Bulk-type resins lost gloss exponentially as the toothbrushing time passed. The gloss also becomes very important when it comes to naturalness; the natural teeth have their own gloss, and if the resin loses that gloss with the brushing, the restoration becomes apparent and requires repairs and maintenance with greater frequency.

In this study, color did not show statistical difference over time because brushing alone does not seem to be capable of this, but in an oral environment there are other factors that may influence the color of the resins. Studies with other factors should be performed to evaluate the color change of this type and resins over time in an oral medium.

Due to the limitations of this study, new studies should be done, not only evaluating aging through brushing simulation but also with immersion in dyes and simulating mechanisms present in the oral cavity, such as De-Re and occlusion, for the observation of other factors also involved in the optical properties of these types of composite resins.

\section{CONCLUSION}

Within the limitations of this study, it could be concluded that toothbrushing was able to increase the roughness and decrease the gloss of bulk fill resins, which made the authors reject the null hypothesis. The translucency and color were not affected by brushing. The three bulk fill resins presented similar behaviors in relation to the optical properties tested.

\section{REFERENCES}

1. Bowen RL. Properties of a silica-reinforced polymer for dental restorations. J AmDent Assoc. 1963;66(1):57-64.

2. SarrettDC, Brooks CN, Rose JT. Clinical performance evaluation of a packable posterior composite in bulk-cured restorations. J Am Dent Assoc. 2006;137(1):71-80.

3. Eick JD, Welch FH. Polymerization shrinkage of posterior composite resins and its possible influence on postoperative sensitivity. Quintessence Int. 1986;17(2):103-11.

4. Manhart J, Chen H, Hamm G, Hickel R. Buonocore Memorial Lecture. Review of the clinical survival of direct and indirect restorations in posterior teeth of the permanent dentition. Oper Dent. 2004;29(5):481-508.

5. Peutzfeldt A. Resin composites in dentistry: the monomer systems. Eur J Oral Sci. 1997;105(2):97-116 
6. Cenci MS, Venturini D, Pereira-CenciT, PivaE, DemarcoFF The effect of polishing techniques and time on the surface characteristics and sealing ability of resin composite restorations after one-year storage. Oper Dent. 2008;33(2):169-76.

7. Marghalani HY.Effect of finishing/polishing systems on the surface roughness of novel posterior composites. J Esthet Restor Dent. 2010;22(2):127-38.

8. llie N, Bucuta S, Draenert M. Bulk-fill resin-based composites: an in vitro assessment of their mechanical performance. Oper Dent. 2013;38(6):618-25.

9. Moorthy A, Hogg CH, Dowling AH, Grufferty BF, Benetti AR, Fleming G.JP.Cuspal deflection and microleakage in premolar teeth restored with bulk-fill flowable resin-based composite base materials. J Dent. 2012;40(6):500-05.

10. da Silva MAB, Fardin AB, de Vasconcellos RCC, Santos LD, Tonholo J, da Silva JG, dos Reis Jl. Analysis of roughness and surface hardness of a dental composite using atomic force microscopy and microhardness testing. Microsc Microanal. 2011;:17(3):446-51.

11. Voltarelli FR, dos Santos-Daroz CB, Alves MC, Caval- canti AN, Marchi GM. Effect of chemical degradation followed by toothbrushing on the surface roughness of restorative composites. J App Oral Sci. 2010;18(6):585-90.

12. Cavalcante LM, Masouras K, Watts DC, PimentaLA, Silikas N. Effect of nanofillers' size on surface properties after toothbrush abrasion. Am J Dent. 2009;22(1):60-4

13. LepriCP,Palma-Dibb RG. Surface roughness and color change of a composite: Influence of beverages and brushing. Dent Mater J. 2012;31(4):689-96.

14. Gönülol N, YilmazF. The effects of finishing and polishing techniques on surface roughness and colour stability of nanocomposites. JDent. 2012;40(Supplement2):e64-e70.

15. Van Groeningen G, Jongebloed W, Arends J. Composite degradation in vivo. Dent Mater. 1986;2(5):225-7.

16. Heintze SD, Forjanic M, Ohmiti K, Rousson V. Surface deterioration of dental materials after simulated toothbrushing in relation to brushing time and load. DentMater.2010;26(4):306-19.
17. Van Ende A, De Munch J, Van LanduytKL, Poitevin A, Peumans M, Van Meerbeek B. Bulk-filling of high C-factor posterior cavities, effect on adhesion to cavity bottom dentin. Dent Mater.2013;29(3):269-77.

18. Van Ende A, De Munck J, Van LanduytK, Van Meerbeek B. Effect of Bulkfilling on the Bonding Efficacy in Occlusal Class I Cavities.J Adhes Dent. 2016:18(2):119-24.

19. Maghaireh, Taha, Alzraikat. Silorane-based Resin Composites. Oper Dent. 2017:42(1):24-34.

20. Barceleiro MO, Soares GM, Espindola 0, Kahn S, Pola Poiate IA, Sampaio Filho HR. Low-shrinkage composites: an in vitro evaluation of sealing ability after occlusal loading. Gen Dent. 2015;63(3):36-40.

21. BucutaS, llie N. Light transmittance and micro-mechanical properties of bulk fill vs. conventional resin based composites. Clin Oral Investig. 2014;18(8):1991-2000.

22. Alrahlah A, Silikas N, Watts DC. Post-cure depth of cure of bulk fill dental resincomposites. Dent Mater.2014;30(2):149-54.

23. Roggendorf MJ, Kramer N, Appelt A, Naumann M, Frankenberger R. Marginal quality of flowable 4-mm base vs conventionally layered resin composite. J Dent. 2011;39(10):643-7.

24. Park J, Song C, Jung J, Ahn S, Ferracane J. The effects of surface roughness of composite resin on biofilm formation of Streptococcus mutans in the presence of saliva. Oper Dent. 2012;37(5):532-9.

25. Sampaio CS, Chiu KJ, Farrokhmanesh E, Janal M, Puppin-Rontani RM, Giannini M, Bonfante EA, Coelho PG, Hirata R. Microcomputed Tomography Evaluation of Polymerization Shrinkage of Class I Flowable Resin Composite Restorations. Oper Dent. 2017;42(1):E16-E23.

26. Arimoto A, Nakajima M, Hosaka K, Nishimura K, Ikeda M, Foxton RM. Translucency, opalescence and light transmission characteristics of lightcured resin composites. Dent Mater. 2010;26(11):1090-7.

\section{Marcos Oliveira Barceleiro}

(Corresponding address)

Rua Dr. Silvio Henrique Braune, 22, Centro, Nova Friburgo, RJ, Bra-

zil. CEP 28625-650;

E-mail: marcosbarceleiro@gmail.com

Date submitted: 2019 Mar 19

Accept submission: 2019 Jun 04 